\title{
LETRAMENTOS EM LÍNGUA PORTUGUESA E INGLESA NA EDUCAÇÃO SUPERIOR BRASILEIRA: MARCOS E PERSPECTIVAS
}

\author{
Vera Lúcia Lopes Cristovão* \\ Universidade Estadual de Londrina \\ Londrina, Paraná, BR \\ Isabela Rodrigues Vieira** \\ Universidade Estadual de Londrina \\ Londrina, Paraná, BR
}

\begin{abstract}
Resumo
Este artigo propõe-se a contribuir com o projeto Iniciativas de Leitura e Escrita no Ensino Superior (ILEES) na América Latina para a consolidação de redes. O objetivo era o de identificar e descrever as iniciativas de ensino e pesquisa em leitura e escrita no Ensino Superior no Brasil. A partir dessa primeira etapa, foi possível identificar os principais núcleos de iniciativas à leitura e escrita. Neste artigo, propomos um trabalho voltado para a segunda etapa dessa pesquisa com a identificação de centros de escrita bem como a análise descritiva de entrevistas com os pesquisadores citados recorrentemente como referências e/ou considerados responsáveis por nucleação de grupos e/ou projetos de letramento(s) em diferentes universidades estaduais e federais do país. Para nossas análises, recorremos ao procedimento de análise do conteúdo temático das entrevistas semiestruturadas por meio da identificação dos segmentos de organização temática (SOT) e como os entrevistados (E) tratam desse tema por meio de segmentos de tratamento temático (STT), proposto por Bronckart (2008) e Bulea (2010). Os resultados mostram cinco centros voltados para leitura e escrita acadêmica no contexto nacional, ao passo que as entrevistas ressaltam aportes teóricos voltados para o letramento e apontam a escassez de trabalho para iniciativas de leitura e escrita nas universidades brasileiras e, em relação à sustentabilidade, ampliação, fortalecimento e reconhecimento são necessidades urgentes, segundo nossas entrevistadas.
\end{abstract}

Palavras-Chave: Letramento; Letramento Acadêmico; Leitura e Escrita no Ensino Superior.

\section{LITERACIES IN PORTUGUESE AND ENGLISH IN BRAZILIAN HIGHER EDUCATION: LANDMARKS AND PERSPECTIVES}

\begin{abstract}
This project aims at contributing to the project called Initiatives of reading and writing in Higher Education (ILEES) in Latin America, whose objective was to identify and describe the initiatives of teaching and research in reading and writing in higher education in Brazil. In this article, we aim at covering the second stage of the research by identifying the writing centers and analyzing the interviews with the researchers mostly cited as references or those considered responsible for gathering research groups and/or literacy projects in different state and federal universities in the country. For our analyses, we use Bronckart's (2008) and Bulea's (2010) methodological framework in order to recognize, in the interviews, the themes (thematic organization segment - SOT) and how the interviewees (E) develop such themes in their discourse through the thematic treatment segments (STT). The results show five writing centers regarding academic reading and writing in the national context. The interviews emphasize theoretical frameworks towards literacy and recognize the lack of initiatives in different Brazilian universities and, regarding sustainability, enlargement, strengthening and recognition are urgent needs, according to our interviewees.
\end{abstract}

Keywords: Literacy; Academic Literacy; Reading and Writing in Higher Education.

\footnotetext{
* Professora associada da Universidade Estadual de Londrina (UEL), membro do Programa de Pós Graduação em Estudos da Linguagem (PPGEL-UEL) e líder do grupo de pesquisa Linguagem e Educação (desde 2002). É bolsista de Produtividade em Pesquisa do CNPq desde março de 2013. Seu endereço de email é veraluciacristovao@gmail.com

** Graduação em andamento em Letras-Português pela Universidade Estadual de Londrina (UEL). Bolsista de Iniciação Científica pelo CNPq do projeto ILEES, sob a orientação da Profa. Dra. Vera Lúcia Lopes Cristovão.
} 


\section{Considerações iniciais}

O projeto ILEES ${ }^{1}$ foi iniciado por investigadores da Universidade da Califórnia, Santa Bárbara (UCSB), sob a coordenação de Charles Bazerman, com o objetivo de "delinear um mapa abrangente do desenvolvimento da leitura e da escrita na educação superior na América Latina por meio do reconhecimento de seus locais de práticas e das iniciativas de investigação". Para tanto, as primeiras ações do projeto incluíram questionários online e entrevistas com professores dos seguintes países: Argentina, Chile, Colômbia e México. Após os resultados oriundos da análise, a pesquisa ampliou-se para mais três países: Brasil, Porto Rico e Venezuela, onde foram utilizadas as mesmas estratégias de pesquisa da primeira fase do projeto para mapear as principais iniciativas de trabalho com a leitura e a escrita no Ensino Superior.

Os objetivos específicos do projeto ILEES são: i) realizar análises e uma possível interpretação dos dados obtidos a partir das entrevistas; ii) estabelecer comparativos entre as entrevistas realizadas no Brasil com as de outros países. Para conciliar nossas ações aos processos desenvolvidos pelos outros países, realizamos entrevistas, por Skype, com uma renomada professora de escrita acadêmica, com uma conceituada pesquisadora no campo de letramentos e responsável por nucleação de pesquisas em escrita e leitura, bem como com a respeitada professora de leitura em língua inglesa no contexto universitário e prestigiada encarregada pelo periódico acadêmico mais citado no questionário online da plataforma do projeto ILEES. Dessa forma, este artigo tem como objetivos identificar centros de escrita bem como apresentar uma análise descritiva de entrevistas com os pesquisadores citados recorrentemente como referências e/ou considerados responsáveis por nucleação de grupos e/ou projetos de letramento(s) em diferentes universidades estaduais e federais do país.

As entrevistas foram transcritas, seguindo as normas do projeto NURC, e analisadas com base nas categorias de Segmentos de Orientação Temática (SOT) e Segmento de Tratamento Temático (STT) ${ }^{2}$ propostas por Bronckart (2008) e Bulea (2010). A análise dos dados consiste em identificar centros de escrita voltados à implementação de propostas de escrita e de leitura no
Ensino Superior no contexto nacional brasileiro e inferir as tendências pedagógicas a partir do levantamento de SOT e STT recorrentes nas entrevistas realizadas. Por questões éticas, os nomes dos entrevistados não serão divulgados, uma vez que objetivamos a identificação dos sentidos construídos pelos entrevistados sobre as iniciativas mapeadas.

Para divulgar e discutir os resultados dessa pesquisa, este trabalho está dividido em seções: primeiramente, discorremos sobre o referencial teórico que fundamenta esta pesquisa; na sequência, apresentamos a metodologia e os procedimentos de análise; e, por fim, expomos os resultados e expressamos nossas considerações finais.

\section{Enquadramento teórico-metodológico}

Este trabalho está ancorado em dois eixos. O primeiro diz respeito à perspectiva do interacionismo sociodiscursivo (ISD) tendo em vista a epistemologia interpretativista da análise de dados. O segundo eixo se refere a conceitos-chave inerentes ao campo dos letramentos.

O ISD, proposto por Bronckart (2003; 2006; 2009), concebe as práticas de linguagem, desenvolvidas a partir de uma situação comunicativa, como formas de ação dos sujeitos no mundo. Devido às línguas serem praticadas de forma verbal e ao movimento ativo e dinâmico que ocorre nas interações verbais, Bronckart (2008, p.109) defende que "a evolução humana deve ser apreendida em um perspectiva dialética e histórica [...], em uma perspectiva que implica um necessário viés dialético", estabelecendo, assim, um dos pilares centrais do ISD. Nessa perspectiva ainda, os conceitos de linguagem e língua estão ancorados na concepção vygotskyana de linguagem como prática social, historicamente constituída. Considerando esse estatuto da linguagem como atividade social, Bronckart assegura ser ela produtora de objetos de sentido e, portanto, constitutiva das representações sociais que construímos.

Assim, entendemos que os textos com os quais trabalhamos nessa pesquisa são exemplares de artefatos simbólicos e semióticos incorporados de representações sociais construídas e em construção com vistas 
à realização da atividade de contribuir para o projeto ILEES. Nesse sentido, o conteúdo temático que compõe o texto expressa entendimentos, saberes e experiências dos agentes-produtores.

Bronckart (2008, p. 162) afirma que para a realização da análise de uma entrevista faz-se necessária "[...] a elaboração de classificações das dimensões do agir-referente consideradas [...] com base nos conteúdos temáticos efetivamente presentes nos textos." Dessa maneira, com base em Bronckart (2008), as entrevistas foram separadas, primeiramente, em duas categorias de segmento:

[...] de introdução, de apresentação ou de lançamento de um tema, os quais chamamos de segmentos de orientação temática; segmentos produzidos pelo entrevistado em resposta a uma questão ou dando prosseguimento a um lance temático do entrevistador, em que o tema é efetivamente tratado, os quais chamamos de segmentos de tratamento temático. (Bronckart, 2008, p. 163).

Bulea (2010) também propõe como procedimento de análise do conteúdo temático a identificação de segmentos de orientação temática (SOT) e de segmentos de tratamento temático (STT). Os SOT referem-se aos temas introduzidos pelo(s) interlocutor(es), ao passo que os STT tratam do teor desenvolvido, da atitude responsiva enunciada, do subtema abordado e exposto nas entrevistas semiestruturadas.

Para compreender como as ações de linguagem são construídas na e pela cultura, moldadas em diferentes discursos, e como esses discursos constituem o agir de linguagem dos sujeitos, apresentamos uma breve definição dos conceitos que permeiam as ações do projeto ILEES: Letramento, Letramento Escolar e Letramento Acadêmico.

Sobre letramento, Marcuschi (2001) defende:

Até mesmo os analfabetos, em sociedades com escrita, estão sob influência do que contemporaneamente se convencionou chamar práticas de letramento, isto é, um tipo de processo histórico e social que não se confunde com a realidade representada pela alfabetização regular e institucional [...]. Frisando mais uma vez o que dizia Street (1995), deve-se ter imenso cuidado diante da tendência à escolarização do letramento, que sofre de um mal crônico ao supor que só existe um letramento. O letramento não é o equivalente à aquisição da escrita. (Marcuschi, 2001, p. 19).

No entanto, em nossa sociedade, a escrita tem extrema importância, podendo, inclusive, ser compreendida como superior à oralidade. Nessa compreensão, aquele que não domina a escrita é considerado "iletrado". Tal visão pode ser observada no contexto do trabalho, em que as funções são divididas de acordo com o nível de conhecimento que cada trabalhador possui. Uma secretária ou uma recepcionista, precisa, obrigatoriamente, dos domínios da leitura e da escrita para a realização de sua tarefa. Contudo, ao levarmos tais profissionais para outro contexto, não o de trabalho, que outras funções teriam a escrita e a leitura? Talvez, fossem necessárias para escrever e ler cartas recebidas, assinar contratos, cheques, ler contas, ler revistas, entre tantas outras coisas. As tecnologias digitais de informação e comunicação parecem ter desacomodado a possível maior relevância da escrita por meio das inúmeras formas de uso da oralidade nas interações virtuais. Seja na expressão escrita, seja na expressão oral, percebemos que cada um possui um nível diferenciado de letramento, que o auxiliará de acordo com as suas necessidades (Marcuschi, 2001).

Na mesma linha de pensamento de Marcuschi, Rojo (2009), ao discorrer sobre letramento, afirma que o termo é diferente de alfabetização, pois considera alfabetização como um processo de conhecer os mecanismos da escrita/leitura, uma vez que uma pessoa letrada pode não possuir esse conhecimento formal, mas como tem familiaridade com seu cotidiano, seu contexto, ela poderá ser considerada letrada. Por exemplo, um indivíduo não tem domínio da escrita, mas ao pegar um ônibus, ou ao comprar algum produto no mercado, ele reconhece os objetos a partir dos seus conhecimentos e do contexto em que está inserido.

Casteluber (2014, p.165) define que "leitura é aqui entendida como o processo de construção de sentido, que vai além da decodificação de grafemas e de fonemas, e que permite aos sujeitos sua participação mais 
212 Vera Lúcia Lopes Cristovão e Isabela Rodrigues Vieira, Letramentos em Língua Portuguesa e Inglesa...

ativa numa sociedade letrada." Com isso, podemos dizer que o conhecimento de leitura, aquela em que conseguimos ir além de apenas ver códigos, contribui para complementar os conhecimentos de letramento. Em outras palavras, a pessoa consegue expandir as suas informações a partir do que já sabe, do que já possui das práticas de letramento, sendo, portanto, necessária a contribuição da escola neste processo.

Segundo Kleiman (2007), o processo de domínio dos códigos pelas pessoas já faz parte do que é conhecido como letramento escolar, já que o indivíduo comumente aprende práticas da escrita e da leitura na escola. Alguns exemplos podem ser o domínio das funções de soletrar, realizar um ditado, escrever uma redação, ler ou responder a questões oralmente, entre tantas outras atividades que podem ocorrer dentro do contexto escolar. Durante os primeiros anos, o professor desenvolve os aspectos da ortografia com o aluno, não necessariamente trabalhando apenas com a junção das sílabas ou a ordem do alfabeto (Kleiman, 2007). Mesmo que alguns alunos apresentem certas dificuldades para desenvolver essas práticas, o professor pode retomar várias vezes o mesmo conteúdo para que o aluno aprenda. Kleiman (2007) cita o exemplo da palavra "dinossauro"; a criança não precisa saber sobre dígrafo ou ditongo, para poder pesquisar sobre o que é este animal, basta estar interessada e possuir um bom orientador. Sendo assim, percebemos que a criança, dentro da escola, poderia sim aprender a ler e a escrever, a soletrar e apropriar as regras de ortografia. Mas ela desenvolveria o letramento escolar com base no que aprendeu na escola, para realizar as suas próprias pesquisas, por meio da curiosidade por um determinado assunto. Sendo assim, o

[...] letramento escolar poderia implicar um conjunto de atividades visando ao desenvolvimento de estratégias ativas de compreensão da escrita, à ampliação do vocabulário e das informações para aumentar o conhecimento do aluno e à fluência na sua leitura. [...] quaisquer dos enfoques e recursos utilizados para ensinar a decodificar, analisar e reconhecer a palavra (que correspondem aos métodos tradicionais de alfabetização) também podem ser considerados práticas de letramento escolar. (Kleiman, 2005, p. 10).
As descobertas tecnológicas têm gerado variações e mudanças nos diferentes contextos sociais, exigindo que novas práticas de letramento se formem no meio social. Para Kleiman (2005)

\begin{abstract}
O letramento abrange o processo de desenvolvimento e o uso dos sistemas da escrita nas sociedades, ou seja, o desenvolvimento histórico da escrita refletindo outras mudanças sociais e tecnológicas, como a alfabetização universal, a democratização do ensino, o acesso as fontes aparentemente ilimitadas de papel, o surgimento da internet. (Kleiman, 2005, p. 21).
\end{abstract}

Os diversos letramentos vêm para atender aos diversos contextos, sendo que um pode complementar o outro, como é o caso do letramento escolar e o acadêmico, visto que os conceitos aprendidos no primeiro irão se complementar no segundo.

Lea e Street (2014) classificam letramentos no meio acadêmico de três formas: modelo de habilidades de estudo; modelo de socialização acadêmica; modelo de letramentos acadêmicos. O primeiro compreende as habilidades de escrita e leitura como individuais e cognitivas. O segundo baseia-se na habilidade de um indivíduo compreender/dominar os temas apresentados nas disciplinas e poder repassar para outras pessoas ou reproduzi-los. O terceiro conta com a formação da identidade e sentido, extrapolando a socialização acadêmica com a participação da pessoa e sua produção textual em comunidades discursivas. Estes modelos apresentados podem ser usados por todas as áreas da universidade.

Lea e Street (2014) mencionam ainda que os modelos de Letramento Acadêmico fazem

[...] uso do modelo de habilidades e de socialização acadêmica, mas vai além do modelo de socialização acadêmica, por exemplo, ao dispensar particular atenção às relações de poder, autoridade, produção de sentido e identidade, implícitas no uso de práticas de letramento em quadros institucionais específicos. Esse modelo não concebe as práticas de letramento como completamente restritas às disciplinas $\mathrm{e}$ às comunidades temáticas; examina, também, como as práticas de letramento advindas de 
outras instâncias (por exemplo, governamental, empresarial, da burocracia universitária) estão comprometidas com aquilo que os estudantes precisam aprender e fazer. (Lea \& Street, 2014, p. 481).

O letramento acadêmico não vai cuidar apenas das temáticas trabalhadas nas disciplinas, mas de todo o contexto que uma pessoa precisa saber/conhecer dentro da academia. As ações de ler um texto, escrever um artigo, desenvolver a fala para apresentações orais e até mesmo formular um pensamento crítico podem propiciar a busca de novos conhecimentos para relacioná-los aos conhecimentos adquiridos por meio de outros tipos de letramento. No contexto universitário, os alunos podem aprender a produzir uma diversidade de textos, além de lerem textos de gêneros diversos. Espera-se com essa prática que o universitário desenvolva um posicionamento social e crítico com domínio de enquadramentos diversos para ações sociais no contexto acadêmico e profissional.

Os letramentos apresentados exigem, em seus eventos, a mobilização de diversos recursos e conhecimentos por parte dos participantes durante as atividades desenvolvidas. Portanto, propiciar diferentes situações de letramentos cria oportunidades de aprendizagem para os participantes, levando-se em consideração as diferenças, dificuldades e necessidades. Ao inserir essa prática para a apropriação da leitura e da escrita, podemos promover o desenvolvimento das ações de linguagem que se tornam mediadoras e constitutivas do social (onde interagem, interesses diversos, valores e objetivos) e o modo como os interagentes avaliam a si mesmos e aos outros quanto às suas capacidades de ação, quanto às suas intenções e quanto às razões para agir nas interações com os outros (Bronckart, 2006).

\section{Metodologia}

Este estudo é norteado pelos seguintes propósitos: i) apresentar um mapeamento dos principais centros de escrita e leitura no Ensino Superior (ES); ii) descrever o conteúdo principal relativo às entrevistas desenvolvidas com professores pesquisadores mais citados na enquete online do projeto ILEES.
A fim de dar conta do primeiro objetivo, fizemos uma busca parametrizada das principais universidades públicas do Brasil, estaduais e federais, por região, com o objetivo de investigar Centros de Escrita (CE) no Ensino Superior. Realizamos a busca pelo nome de cada universidade pública do país, sendo que, procurávamos apenas CE que trabalhassem com as seguintes palavraschave: Escrita; Leitura; Letramento Acadêmico. No Brasil, encontramos cinco universidades que continham os centros específicos de Escrita e Leitura no Ensino Superior, como podemos observar na imagem a seguir:

Figura 1: Universidades que possuem Centros de Escrita no Brasil

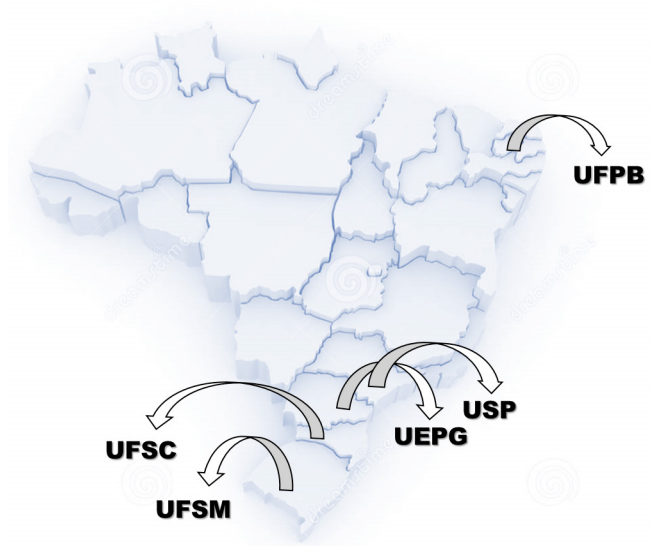

Fonte: ILEES Brasil, 2015 (http://portuguese.ilees.org/).

A segunda parte diz respeito à análise das entrevistas realizadas com três pesquisadoras na área de Linguística Aplicada no Brasil. Duas delas foram as mais citadas como influentes na área de ensino e pesquisa em leitura e escrita no ensino superior e uma é tanto responsável pela revista acadêmica mais citada como fonte de consulta e possível espaço de publicação na área como influente na área de ensino de leitura em língua inglesa em cursos no meio virtual.

Para a análise das entrevistas, utilizamos a metodologia proposta por Bronckart (2008) e Bulea (2010) que consiste em identificar, nas entrevistas, as temáticas para uma melhor compreensão do objeto a ser pesquisado.

Por uma questão metodológica, a seguir ilustramos como a entrevistadora do projeto ILEES introduz um segmento de organização temática (SOT) e como 
214 Vera Lúcia Lopes Cristovão e Isabela Rodrigues Vieira, Letramentos em Língua Portuguesa e Inglesa...

os entrevistados (E) tratam desse tema por meio de segmentos de tratamento temático (STT).

ILEES (SOT): Então, a primeira pergunta, eu gostaria de é::: ouvir de você, como você chamaria esse campo relacionada, esse campo relacionado a, é:: escrita e leitura é:: no ensino superior?

E1 (STT): O grande campo é estudos de letramento, se for trabalhar no ensino superior, letramento acadêmico. [...] letramentos ou multiletramentos, porque os textos hoje não são só verbais, mas são não-verbais também. Então, estudos de multiletramento acadêmicos ou estudos de multiletramentos.

E2 (STT): Eu tenho chamado sempre por estudos de letramento acadêmico.

E3 (STT): É eu coloco dentro de Linguística Aplicada.

Consideramos que no SOT - inserção de uma temática - a entrevistadora introduz o tema por meio de um questionamento, que, de modo geral, poderia ser sintetizado em "como você chamaria esse campo relacionado à leitura e à escrita no Ensino Superior?" que suscitará as respostas das entrevistadas. Essas respostas serão o modo como as entrevistadas tratarão desse tema, dando as possíveis respostas. Assim, o STT se refere às designações dadas às formas como elas denominam os campos relacionados à leitura e à escrita; nesse caso, E1 denomina como "estudos de letramento", "letramento acadêmico" e "estudos de multiletramentos"; E2 de "estudos de letramento acadêmico"; e E3 de "Linguística Aplicada".

Tendo em vista o escopo deste artigo, não consideramos necessária a inclusão de excertos para as análises, mas sintetizamos, em uma tabela, os SOT e STT identificados nas três entrevistas semiestruturadas, seguida de uma discussão.

\section{Análise}

As análises foram realizadas em dois momentos. Um dedicado aos CE, e outro às entrevistas. Os principais pontos identificados em cada um dos momentos são apresentados.

Com relação ao primeiro objetivo, a tabela 1 apresenta as universidades, os nomes dos CE e os seus lí- deres. Na sequência, delineamos uma breve descrição de cada CE.

Quadro 1: Relação de universidades, Centros de Escrita (CE) e seus líderes

\begin{tabular}{|l|l|l|}
\hline Universidade & Centros de escrita & Líderes \\
\hline $\begin{array}{l}\text { Universidade Federal de } \\
\text { Santa Maria - UFSM }\end{array}$ & $\begin{array}{l}\text { LabLeR - Laboratório } \\
\text { de Pesquisa e Ensino } \\
\text { de Leitura e Redação }\end{array}$ & $\begin{array}{l}\text { Désirée Motta- } \\
\text { Roth e } \\
\text { Graciela Hendges }\end{array}$ \\
\hline $\begin{array}{l}\text { Universidade de São } \\
\text { Paulo - USP }\end{array}$ & $\begin{array}{l}\text { Laboratório de Le- } \\
\text { tramento Acadêmico }\end{array}$ & $\begin{array}{l}\text { Marília Mendes } \\
\text { Ferreira e } \\
\text { Eliane Gouvêa } \\
\text { Lousada }\end{array}$ \\
\hline $\begin{array}{l}\text { Universidade Estadual } \\
\text { de Ponta Grossa - }\end{array}$ & $\begin{array}{l}\text { Laboratório de } \\
\text { Estudos } \\
\text { do Texto }\end{array}$ & $\begin{array}{l}\text { Djane Antonucci } \\
\text { Correa }\end{array}$ \\
\hline $\begin{array}{l}\text { Universidade Fedral de } \\
\text { Santa Catarina - UFSC }\end{array}$ & Cátedra Unesco & $\begin{array}{l}\text { Emérita Leonor } \\
\text { Scliar-Cabral }\end{array}$ \\
\hline $\begin{array}{l}\text { Universidade Federal da } \\
\text { Paraíba - UFPB }\end{array}$ & Cátedra Unesco & $\begin{array}{l}\text { Regina Celi } \\
\text { Mendes Pereira }\end{array}$ \\
\hline
\end{tabular}

Fonte: ILEES Brasil, 2015 (http://portuguese.ilees.org/)

O Laboratório de Pesquisa e Ensino de Leitura e Redação (LabLeR - UFSM/ disponível em: http:// w3.ufsm.br/labler/) foi desenvolvido em 1997 como uma opção de formação complementar para os alunos de graduação e pós-graduação do Departamento de Letras Estrangeiras Modernas da UFMS, bem como para professores da rede estadual. O Laboratório tem por objetivo capacitar os alunos na prática de pesquisa, ensino e extensão na área de Linguística Aplicada, por meio da conscientização das práticas discursivas contemporâneas. O LABLER trabalha com o ensino e aprendizagem da linguagem, dos processos da leitura, da escrita e dos multiletramentos, além da elaboração de materiais didáticos.

O Laboratório de Letramento Acadêmico ${ }^{3}$ foi criado em 2011 pelo Departamento de Letras Modernas da Faculdade de Filosofia, Letras e Ciências Humanas da USP. A criação do laboratório se deve à preocupação da faculdade com a comunicação, a escrita e a leitura em língua materna e estrangeira de seus alunos que estavam acostumados com os gêneros voltados para provas de vestibulares. O laboratório atende alunos de graduação, pós-graduação e docentes por meio de palestras, workshops e atendimentos individuais. 
O Laboratório de Estudos do Texto foi aprovado na UEPG como parte de um Programa de Extensão em 2007. Atualmente, exercem o trabalho no laboratório quatorze (14) professores da universidade, além de professores em formação. O seu objetivo é o de trabalhar com a escrita e a análise de textos por meio de cursos e minicursos, projetos de pesquisa ligados ao programa de extensão, projetos de formação de professores, trabalhos de leitura e escrita para atender às diferentes classes sociais e estudos que abordem temas sobre as necessidades da educação na atualidade.

Além da identificação desses três centros mais ligados às próprias universidades, também reconhecemos a implantação da Cátedra UNESCO ${ }^{4}$ para o desenvolvimento da leitura e escrita para alunos da graduação e pós-graduação em duas Instituições de Ensino Superior brasileiras. Na Universidade Federal de Santa Catarina (UFSC), desde 2011, coordenado pela Profa. Emérita Leonor Scliar-Cabral, ao passo que na Universidade Federal da Paraíba (UFPB) o convênio foi firmado em 2015. Na UFPB, a iniciativa teve como solo fértil o Ateliê de Textos Acadêmicos (ATA), projeto vinculado ao Programa de Pós-Graduação em Linguística, coordenado pela Profa. Dra. Regina Celi Mendes Pereira. Algumas das contribuições esperadas pelas IES conveniadas à Cátedra são o apoio entre os diferentes países e IES participantes, promovendo a possibilidade do desenvolvimento de atividades de pesquisa, e a consolidação de parcerias acadêmicas em diferentes níveis.

A segunda parte deste estudo dedica-se à análise das entrevistas com as autoras mais citadas na plataforma online do Projeto ILEES. As entrevistas foram gravadas, transcritas e classificadas em temáticas com a autorização das participantes.

Bulea (2010) defende que a discussão entre pesquisador e protagonistas, proporcionada pela entrevista, permite abordar os níveis da textualidade da interpretação do agir. Tendo em vista o objetivo de trazer à tona o conteúdo temático desenvolvido, nos detivemos à identificação dos SOT e STT. A entrevista semiestruturada não tem uma estipulação intransigente das perguntas e sua ordem, e oferece flexibilidade de explorar as questões propostas podendo ser complementadas a partir das informações que vão sendo dadas e permitindo adaptações e reorientações (Richardson et al., 1985).

No caso deste estudo, foram solicitadas informações às entrevistadas por meio de entrevista semiestruturada com base em perguntas, conforme apresentamos no quadro 2 .

Quadro 2 - SOT/ temas que nortearam a entrevista semiestruturada

1 - Saudação, agradecimento e permissão para gravar Esta entrevista é parte do Projeto ILEES. Pretendemos descrever experiências/iniciativas de leitura e escrita no ensino superior no Brasil.

2 - perguntas:

Como chamaria esse campo de pesquisa/estudo?

Em sua opinião, qual foi o começo do desenvolvimento desse campo?

Quais foram os marcos para o desenvolvimento desse campo? Seu nome foi dos mais citados como uma das grandes influências para esse campo no Brasil. A que você atribuiria essa influência e se poderia contar sobre seu envolvimento com o campo da leitura e da escrita (no ensino superior)? Com quem trabalha nesse campo de pesquisa/estudo? Você conhece grupos ou redes de trabalho nesse campo? Conhece outras iniciativas?

E a sustentabilidade para esse campo de pesquisa? Qual o estatuto deveria ter esse campo na universidade. De serviço? De Programa Complementar? De uma política institucional?

Que construtos teórico-metodológicos são usados nesse campo?

Você acredita em uma articulação entre ensino e pesquisa nesse campo? Como?

Que outras informações gostaria de acrescentar?

A partir desse roteiro de perguntas, as entrevistas foram feitas em julho de 2014. Ressaltamos que esse roteiro não foi seguido rigidamente com as três entrevistas, ora porque pudemos excluir alguma pergunta à medida que as informações já atendiam ao propósito da pesquisa, ora porque um dado se articulava a uma questão em uma ordem diferente daquela proposta.

A partir dessas informações, voltamo-nos para a última etapa desse estudo, que consiste em analisar como os SOT sugeridos pelo representante do ILEES, no papel de entrevistadora, foram sendo tratados pelos entrevistados.

A tabela 2 sintetiza os SOT e STT identificados nas entrevistas ocorridas na segunda etapa do projeto. 
Tabela 1: SOT introduzidos pela entrevistadora e STT desenvolvidos pelas entrevistadas.

\begin{tabular}{|c|c|c|}
\hline SOT & STT E1 & STT E 2 \\
\hline $\begin{array}{l}\text { CAMPO DE } \\
\text { PESQUISA }\end{array}$ & $\begin{array}{l}\text { Estudos de Letramento; } \\
\text { Estudos de Letramento Acadêmico; } \\
\text { Estudos de Multiletramentos Acadêmi- } \\
\text { cos. }\end{array}$ & $\begin{array}{l}\text { Estudos de Letramento } \\
\text { Acadêmico. }\end{array}$ \\
\hline $\begin{array}{l}\text { PROJETO COM } \\
\text { ENVOLVIMEN- } \\
\text { TO DIRETO }\end{array}$ & $\begin{array}{l}\text { Curso de Academic Writing; } \\
\text { Disciplina de Escrita Acadêmica; } \\
\text { LabLeR com cursos de extensão de } \\
\text { Escrita Acadêmica e de Inglês Instru- } \\
\text { mental; } \\
\text { Autora de livro de redação acadêmica; } \\
\text { Parcerias internas, por exemplo, com } \\
\text { Hendges. }\end{array}$ & $\begin{array}{l}\text { Letramento para a comunidade; } \\
\text { Estudos de } \\
\text { Letramento } \\
\text { do professor, de sua profissão e da } \\
\text { escrita do professor; } \\
\text { Sala Educativa; } \\
\text { Grupo de pesquisa temática - Le- } \\
\text { tramento do Professor. Rede com } \\
\text { PUC- Minas, UNIFESP, UFSCAR, } \\
\text { UNITAU, Federal e Estadual da Ba- } \\
\text { hia, Federal do Rio Grande do Norte } \\
\text { e Federal da Paraíba, Federal de São } \\
\text { Carlos. }\end{array}$ \\
\hline
\end{tabular}

\begin{tabular}{ll}
\hline CONHECIMEN- & Escola de Educação da \\
TO DE OUTROS & UFMG com Maria Lúcia Castanheira; \\
PROJETOS & Perspectiva dos \\
& Letramentos Acadêmicos de Brian \\
& Street; \\
& Redação acadêmica na USP com Marí- \\
& lia Ferreira; \\
& Trabalhos de Paula Carlino, na Argen- \\
& tina.
\end{tabular}

\section{Conexão com}

grupos de pesquisa da Rede Letramento do Professor; grupo Identidade, linguagem e formação do professor (PUC-Minas), Práticas formativas e profissionais (UNITAU), Núcleo de Estudos e Linguagens e Tecnologias e Rasura (Federal da Bahia), AULA (UNICAMP), NELA (Santa Catarina.

Paula Carlino, na Argentina, Cristina Sabalo,no Peru, e Asociación Colombiana de Universidades.

\section{MARCOS HISTÓRICOS}

\author{
Vygotsky: conceito de Aprendizagem: \\ Parcela léxico-gramatical: Linguística \\ Sistêmico Funcional; \\ Atividade Social, Instituição e Lingua- \\ gem: Bakhtin; Lave e Wenger Theory; \\ Gênero: John Swales; \\ Análise Crítica do Discurso: Fair- \\ clough, Roz Ivanic, Romy Clark \\ Relações Sociais, relações d poder e \\ criticidade: Paulo Freire.
}

\section{Estudos de Street;}

Viés antropológico;

Abordagens etnográficas; estudos culturais; metodologia analítica com o conceito de dialogismo de Bakhtin; necessidade de um grande projeto sobre a leitura e a escrita na universidade e de um "abrigo institucional"; carência de uma associação e de uma política institucional.

\section{STT E 3}

\section{Linguística}

Aplicada.

IngRede, curso de leitura no ensino superior; Editora de periódico brasileiro qualis A1.

\section{ILEES;}

LabLeR;

Projeto da PUC de SP;

Grupo da Ana Rachel;

Grupo em Pernambuco;

GT da ANPOLL como o de Gêneros e Linguagem e Tecnologia.

\author{
Motta-Roth, \\ Cristovão et al.; \\ Street; \\ Bazerman; \\ Miller; \\ Swales.
}

$\begin{array}{ll}\text { SUSTEN- } & \text { Pesquisa aplicada com benefícios soci- } \\ \text { TABILIDADE } & \text { ais; política institucional com aumento } \\ \text { DE CAMPO DE } & \text { do quadro de pessoal; } \\ \text { PESQUISA } & \text { Programa governamental como para a } \\ & \text { Internacionalização das universidades ; } \\ & \text { Reconhecimento na estrutura univer- } \\ & \text { sitária; ampliação, fortalecimento e } \\ & \text { respeitabilidade para a área. }\end{array}$

COMENTÁRIOS O uso de diferentes teorias (diálogos dentro das teorias ).
Visibilidade da pesquisa; Financiamento internacional para as pesquisas; reformulação curricular dos cursos de Letras; Campo de Serviços e Políticas institucionais ; Articulação entre Ensino, pesquisa e extensão ; Contribuição e responsabilidade social.

\author{
Necessidade de \\ cursos de escrita \\ acadêmica \\ para a universidade \\ como um todo; importância de \\ aumentar a força de trabalho; \\ articulação ensino, pesquisa e \\ extensão.
} seja estabelecido no Brasil

Fonte: ILEES Brasil, 2015. 
Identificados os SOT e STT, passamos à análise descritiva mais detalhada de cada um dos temas.

Em relação ao campo, como podemos observar, as entrevistadas deram respostas semelhantes, mencionando os diferentes tipos de letramento, mais especificamente o letramento acadêmico, inserido no campo de pesquisa escrita e leitura no ES, na área de Linguística Aplicada. Como vimos, no referencial teórico, há diversos tipos e conceitos diferentes de letramento em função da especificidade da participação do indivíduo em suas esferas de atividade. No caso da entrevista, pela conversa ser voltada para o contexto universitário, o campo do Letramento Acadêmico foi privilegiado, na área da Linguística Aplicada.

A primeira entrevistada, E1 faz um complemento de que não seria apenas o Letramento Acadêmico, pois, existem diversos textos no meio universitário, como os não verbais. Na mesma linha dos autores apresentados na fundamentação teórica, Carnin (2014) mostra que o estudante universitário aprende diversas habilidades dentro da academia para atender às suas necessidades e às demandas desse contexto, incluindo-se a produção verbal em apresentações orais. Podemos entender que tanto Carnin (2014) como E1 acreditam que o Letramento Acadêmico se expande de acordo com a necessidade do aluno, nesse caso, a questão da oralidade, abordando, assim, o conceito de Multiletramentos Acadêmicos.

O segundo SOT aborda quais são e em que consistem os projetos dos quais os entrevistados fazem parte.

E1 conta sua trajetória desde a realização do doutorado cujo escopo já tinha relação com a questão da escrita acadêmica até sua inserção no ensino, pesquisa e extensão depois da conclusão de seu doutorado. Em seu relato, E1 narrou ter iniciado atendendo uma demanda de sua universidade em ofertar um minicurso de redação acadêmica, em inglês, para alunos da graduação em Letras e professores de outras áreas. Esse curso foi a base para a primeira versão do livro de E1 sobre essa temática. Na sequência, com a reforma da pós-graduação em Letras de sua instituição de ensino superior (IES), passa a ofertar a disciplina de redação acadêmica, em português, para alunos do programa e de outros, de áreas diversas (como Literatura, Geografia, Economia, entre outras). Essa oferta foi feita de 1995 a 2002. Com a aprovação do projeto Laboratório de Pesquisa e Ensino de Leitura e Redação (LabLeR) pela FAPERGS, foi criado, em 1997, o programa LabLeR, no qual alunos da graduação e da pós-graduação trabalham com ensino de instrumental de línguas estrangeiras e redação acadêmica em português. Nesse contexto, E1 passa a ofertar redação acadêmica como curso de extensão para alunos da pós-graduação, à noite, com a participação de alunos da graduação como parte de seu processo de formação de novos pesquisadores e de professores com qualificação em letramento acadêmico e exercício pedagógico desde sua inserção no programa/laboratório.

E2 também retoma seu percurso e relata ter iniciado, nos anos 90, com alfabetização de Educação de Jovens e Adultos (EJA), o projeto de letramento para a comunidade. Foi nesse mesmo contexto que o projeto se transformou em letramento do professor, com trabalho na formação do professor e nos estudos da língua escrita. Por volta dos anos 2000, com os estudos de Street, E2 se envolve com letramento acadêmico. Em relação ao contexto universitário, E2 cita resultados de avaliações envolvendo a leitura e a escrita e as dificuldades vivenciadas na formação universitária. Enfatiza suas inúmeras pesquisas e sua grande rede formada por pesquisadores e pós-graduandos de diferentes grupos de pesquisas de várias universidades (PUC-Minas, UNIFESP, UNITAU, Universidades Federal da Bahia, Universidade Estadual da Bahia, Universidade Federal do Rio Grande do Norte, Universidade Federal da Paraíba e Universidade Federal de São Carlos) desenvolvendo trabalhos investigativos em torno do letramento do professor.

Frente às dificuldades apresentadas pelas entrevistadas, há indícios de que lacunas nas práticas de leitura e de escrita poderiam ser amenizadas se os alunos tivessem a oportunidade de realizar práticas de leitura e escrita com gêneros da esfera acadêmica, tais como: fichamento, relatório, resenha, resumo, artigo científico, apresentação oral, entre outros. Diante do exposto, os centros de escrita dentro das universidades parecem poder contribuir para a formação dos alunos, no sentido de conhecer e saber lidar com os gêneros acadêmicos, seja ao produzir um relatório, um trabalho de conclusão de curso ou tantas outras produções textuais.

E3 descreve o Inglês na Rede (IngRede) como um projeto de 'remedial work' que visa ao desenvolvimento 
de leitura e de hábitos de leitura em uma comunidade de prática por área. As diversas atividades propostas promovem a oportunidade de leitura para além da busca de informação e agrupam os alunos em várias comunidades de prática com interesses específicos, por meio da participação em debates, na partilha de um texto que contribua para a discussão e na construção de um glossário, por exemplo. E3 também enfatiza o IngRede como um grande projeto de formação de professores (inicial e continuada) porque envolve bolsistas da graduação e da pós-graduação. Enquanto rede/unidade institucional, seu funcionamento se deu na elaboração do material com a contribuição de profissionais de diferentes IES, de distintas regiões.

Em relação à revista para a qual atuou como editora-chefe durante mais de 08 anos, E3 justifica a grande penetração do periódico em função de inúmeras razões: sua agilidade, sua indexação ao Scielo, sua boa avaliação (qualis A1), sua veiculação de quatro volumes anuais (dois temáticos e dois gerais) e publicações de artigos em inglês. E3 enfatiza as condições e o apoio que a revista tem para essa bem-sucedida empreitada. A revista recebe recurso financeiro de dois órgãos de fomento, apoio logístico e financeiro da universidade em que está sediada (UFMG), recursos humanos, e alta demanda por publicação. Essas circunstâncias favorecem a valorização da revista que já veiculou "grande quantidade de textos" na área de estudos de letramento acadêmico.

O terceiro SOT é sobre o conhecimento de outros projetos que envolvem a leitura e a escrita nas universidades. Cada entrevistado relatou experiências de grupos diferenciados, mas todos realizam ou realizaram algum trabalho voltado para o ensino de leitura e escrita no Ensino Superior.

Ao longo da entrevista, E1 citou a escassez de iniciativas por muitos anos, mas que, a partir de 2013, tem havido uma explosão de pesquisas, trabalhos e propostas pedagógicas nessa área. Reconhece os empreendimentos de Street como um lócus de investigação e de teorização e os associa aos trabalhos da Escola de Educação da UFMG, com Maria Lúcia Castanheira. Também indica a USP, com o Laboratório de Letramento Acadêmico, coordenado por Marília Ferreira. Ao final, E1 faz questão de incluir as iniciativas de outros países como a de Paula Carlino, na Argentina.

A segunda entrevistada discorreu sobre sua conexão com grupos de pesquisa de diferentes IES, formando a Rede Letramento do Professor. Citou diferentes grupos de pesquisa como Identidade, Linguagem e Formação do Professor (PUC-Minas), Práticas Formativas e Profissionais (da UNITAU), os grupos Estudos, Linguagens e Tecnologias da Federal da Bahia e o grupo Rasura. Da UNICAMP mencionou o grupo AULA e de Santa Catarina, o grupo NELA. E2 também cita iniciativas na América Latina.

E3 menciona várias iniciativas: i) o projeto ILEES; ii) o grande projeto coordenado por Désirée Motta-Roth ${ }^{5}$; iii) o projeto do grupo que era liderado pela Anna Rachel Machado, da PUC-SP; iv) as atividades do grupo de Angela Dionísio, em Pernambuco; v) GTs da ANPOLL, como o de Gêneros Textuais/Discursivos e de Linguagem e Tecnologia.

A partir da definição de Letramento proposta por Casteluber (2014), podemos depreender que o ensino de leitura vai além de decifrar códigos e, para que o aluno entenda isso, é preciso trabalhar com a leitura de formas diferenciadas. Acreditamos que é para estes fins que tais grupos de pesquisa existem. Além da pesquisa em si, os grupos desenvolvem formas de se trabalhar com um texto, tanto em relação à leitura quanto em relação à escrita. Podemos perceber, também, a forma como as entrevistadas prosseguem o STT, que se volta de forma positiva para o que foi proposto no SOT.

O SOT seguinte aborda os principais marcos históricos de acordo com cada entrevistada. Esta pergunta está mais relacionada aos autores que contribuíram para a linha de pesquisa de cada um dos entrevistados e que abordam temas voltados para a leitura e a escrita. E1 cita pelo menos três grandes marcos. Primeiramente uma teoria de aprendizagem com base em Vygotsky. Articulados a essa teoria estão os conceitos cunhados por Lave \& Wenger de comunidades de prática e de participação periférica legítima como a instância de aprendizagem. Em relação à língua e a gênero, toma Bakhtin como uma referência guarda-chuva. Em nível léxico-gramatical, outro marco é a Linguística Sistêmico Funcional. Ainda para gênero, também convoca John Swales e a Sociorretórica para pensar em sistema 
de gênero, conjunto de gênero e instituição. Em relação aos letramentos acadêmicos, nomeia como perspectiva crítica a Análise Crítica do Discurso, indicando Fairclough, Roz Ivanic e Romy Clark para o trabalho com questões de relações sociais e resistência. Ademais, acrescenta Paulo Freire como referência para o estudo de relações de poder e criticidade.

E2 indica um viés antropológico, influenciado pelos estudos do letramento de Street, e um enfoque social, abordagens etnográficas, estudos culturais e metodologia analítica com o conceito de dialogismo de Bakhtin. Ao ponderar sobre marcos, E2 evidencia a necessidade de um grande projeto sobre a escrita acadêmica, sobre a leitura e a escrita na universidade e cita o ILEES como exemplo. Menciona também a possibilidade de uma associação como há na Colômbia, por exemplo. Salienta ainda que há iniciativas parciais e locais, como eventos em áreas disciplinares como na Educação e na Linguística Aplicada, mas considera necessário um "abrigo institucional". A pesquisadora acrescenta as avaliações externas e a tecnologia digital de informação e comunicação (cultura digital) como marcos em função de tipos de pressão sob a escrita e a leitura. Mais uma vez, E2 enfatiza o valor da iniciativa empenhada pelo projeto ILEES e a possibilidade de instituição de uma política institucional para leitura e escrita no contexto universitário. E2 encerra seu turno de fala manifestando faltar marcos para que essa área esteja estabelecida no Brasil.

E3 menciona se basear em Bazerman e Miller, da Sociorretórica, Swales, do ESP, Brian Street, dos estudos de letramento, bem como nos trabalhos de pesquisadores dos estudos de gêneros como as publicações dos grupos de pesquisa liderados por Désirée Motta-Roth, Vera Cristovão, Adair Bonini, Adair Gonçalves, Acir Karwoski e Roxane Rojo.

Nos excertos que desenvolvem essa temática, podemos notar que alguns autores são recorrentes como referências às entrevistadas. Essa anuência aconteceu com autores da linha de estudos de gêneros e com a referência de Street para estudos de Letramento, Letramento Acadêmico, Letramento Social e Multiletramento. Lea e Street (2014) acreditam que o aluno, ao entrar em uma universidade, precisa se adaptar a esse novo contexto para que possa atender às demandas propostas pela uni- versidade, como escrever um artigo científico ou uma resenha. Isso retoma o que já foi abordado no segundo SOT da entrevista, em que o contexto universitário possui algumas exigências diferenciadas da educação básica.

O penúltimo SOT aborda a sustentabilidade do campo de pesquisa. Do ponto de vista das entrevistadas, essa sustentabilidade seria a resposta para se continuar ou ampliar uma pesquisa.

A pesquisa aplicada foi referida por E1 como necessária em função de seu vínculo e compromisso com a sociedade. Ou seja, a pesquisa precisa ser de intervenção no mundo. Além disso, enfatiza a importância de uma política institucional e a expansão do quadro de recursos humanos que possam trabalhar com questões como as de multiletramentos acadêmicos. Adiciona ainda a indispensabilidade de um programa governamental de caráter interdisciplinar. Para E1, sustentabilidade implica "ampliação, fortalecimento, respeitabilidade" e reconhecimento na estrutura universitária.

Em relação à sustentabilidade, E2 enumera algumas condições como i) a visibilidade da pesquisa; ii) financiamento internacional para as pesquisas; iii) reformulação curricular dos cursos de Letras para que se aborde mais as questões sociais e nossa responsabilidade social em tratá-las; iv) campo de serviços, já que trabalhamos na articulação entre ensino, pesquisa e extensão; v) instauração de políticas institucionais e de trabalho e pesquisa em rede.

$\mathrm{E} 2$, por exemplo, menciona o alto índice, segundo uma pesquisa realizada pelo INAF, de alunos que estão no ensino superior, mas não possuem a habilidade básica de escrita. Casteluber (2014) define que a leitura vai além do simples processo de decodificar. Sendo assim, notamos pelo exposto nas entrevistas que é preciso realizar pesquisas capazes de extrapolar os muros das universidades, expandindo-as para a sociedade em geral.

E3 ressaltou seu constante acompanhamento dos trabalhos disseminados por pesquisadores brasileiros e seu interesse em outras áreas, como a de aquisição.

Mediante as respostas apresentadas nas entrevistas e com base na tabela 1 de SOT e STT, percebemos que, para que ocorra a internacionalização das universidades, primeiro é necessário expandir o ensino da escrita acadêmica dentro da própria universidade. No entanto, 
para que isso aconteça, é necessária a implementação de políticas governamentais que possam beneficiar e possibilitar apoio pedagógico às instituições de ES. Consequentemente, sem o apoio, não há articulação entre o ensino, a extensão e a pesquisa. Apesar da defesa feita por Rojo (2009) e Marcuschi (2001) de que até mesmo os analfabetos possuem algum tipo de letramento, as entrevistadas abordam que a pesquisa deveria ir muito além de apenas concordar ou conformar com esse dado e lidar com essas questões sociais.

Por fim, as entrevistadas tiveram um espaço para fazerem um comentário final.

A entrevistada E1 explicita que uma boa experiência e uma oportunidade de aprendizagem seriam possibilitadas se cada grupo de pesquisa realizasse um curso ou um minicurso sobre os trabalhos que desenvolvem em sua respectiva universidade. Tal ação viabilizaria troca de conhecimento, promovendo divulgação, diálogo, discussão entre os próprios acadêmicos a respeito dos temas das pesquisas. Outrossim, E1 ratifica a possibilidade de diálogos teórico-metodológicos por parte dos pesquisadores em suas investigações.

E2 defende faltar marcos para que haja reconhecimento dessa área/desse campo e ratifica a possível contribuição do ILEES para isso. Já E3, ratifica não se considerar uma especialista nessa área, mas uma boa leitora de referenciais teóricos e pesquisas desenvolvidas por grupos brasileiros.

Para apresentar uma breve síntese, orientamo-nos pelos mesmos SOT propostos relacionados ao campo disciplinar, aos projetos desenvolvidos, às iniciativas de outrem, aos marcos e perspectivas de sustentabilidade. As entrevistadas têm envolvimento com o que reconhecem como Letramentos Acadêmicos e Multiletramentos na área de Linguística Aplicada. Duas delas têm parcerias com membros internos aos seus próprios projetos e uma criou um grande núcleo de pesquisa com pesquisadores de diversas universidades. Entretanto, foi reiterada a escassez de diálogos, de parcerias e de redes de pesquisa com questões nesse escopo. Como marcos, houve tanto menções a autores quanto a perspectivas teórico-metodológicas. Em relação à sustentabilidade, ampliação, fortalecimento e reconhecimento foram as premissas corroboradas pelas entrevistadas.

\section{Considerações finais}

Este artigo apresentou resultados da segunda etapa do Projeto Iniciativas de Leitura e Escrita no Ensino Superior (ILEES). Durante o projeto, por meio das pesquisas parametrizadas pelas regiões do Brasil, pudemos perceber a escassez e a necessidade de expansão do número de $\mathrm{CE}$ nas universidades brasileiras. Esse elemento pode ser articulado ao dado da primeira fase de que as iniciativas de ensino se dão primordialmente em disciplinas do currículo. Dentre as universidades públicas brasileiras, encontramos cinco que continham um laboratório ou CE voltado para o ensino e aprendizagem da leitura e da escrita, tanto em língua materna como em língua estrangeira, incluindo as duas instituições com a Cátedra UNESCO. Constatamos também, pelas entrevistas, que há demandas institucionais para os estudos dos letramentos, já que relatam haver procura por parte dos próprios alunos, que querem e precisam sanar suas dificuldades, em nível da leitura ou da escrita, bem como o interesse do próprio pesquisador.

Pelas entrevistas, concluímos que, apesar de os alunos já terem experienciado o letramento escolar, os conceitos abordados em uma universidade são de outra complexidade e precisariam de espaços específicos para serem tratados longitudinalmente no nível terciário. A proposta de escrita acadêmica em muitas universidades norte-americanas, por exemplo, é que ela possa ocorrer ao longo da formação profissional da graduação em, pelo menos, quatro disciplinas, sendo, duas gerais e duas específicas para a área disciplinar.

Além da relevância da aprendizagem do métier acadêmico, interpretamos que duas entrevistadas aproximaram as questões de multiletramentos à responsabilidade social que temos como educadores e pesquisadores, já que enfatizaram a necessidade de as pesquisas ultrapassarem os limites das universidades para assumirmos o compromisso para com questões de vulnerabilidade social.

Diante do quadro apresentado, vemos a necessidade de expansão no número de CE/laboratórios de (multi) letramentos acadêmicos em mais universidades brasileiras, com a oferta de cursos, oficinas ou disciplinas e atendimentos individuais voltados para o ensino de leitura e escrita. Essa expansão contribuiria para a formação 
dos alunos, assim como tem acontecido na UFSM, USP, UEPG, UFSC e UFPB. Além disso, os centros devem ser mais abrangentes, devem divulgar mais as experiências e materiais, assim como fortalecer o diálogo interinstitucional para que essas iniciativas sejam expandidas.

Com domínio nos (multi)letramentos acadêmicos, os alunos teriam maior participação em suas comunidades discursivas e maior engajamento com a construção de conhecimento e as possibilidades de divulgação científica. Quando o aluno não possui os domínios que a universidade exige, fica mais complicado para ambos, professor e aluno, obterem êxito em suas atividades.

\section{Agradecinmento}

Agradecemos a professora Maria Ilza Zirondi por sua colaboração externa no presente artigo.

\section{Notas}

1. O Projeto Iniciativas de Leitura e Escrita no Ensino Superior (ILEES) na América Latina foi concebido com o objetivo de mapear as tendências pedagógicas e de pesquisa na área de leitura e escrita nos últimos anos (disponível em: http://portuguese.ilees.org/). O projeto é de autoria do Professor Dr. Charles Bazerman, da Universidade de Santa Bárbara (UCSB), na Califórnia, e conta com a participação de pesquisadores da Argentina, Brasil, Chile e Colômbia. A equipe brasileira tem como líder a professora Dra Vera Lúcia Lopes Cristovão (UEL/ CNPq), Ana Valéria Bisetto Bork (UTFPR), Francini Percinoto Poliseli Corrêa (UNESPAR), e Isabela Rodrigues Vieira (G-UEL). Com relação ao desenho metodológico, agradecemos Natalia Ávila Reyes (Chile) e Elizabeth Narváez Cardona (Colômbia). A participação de Vera Lúcia Lopes Cristovão no Projeto ILEES foi viabilizada pela sua estada como professora pesquisadora na Universidade da California, campus de Santa Bárbara, com bolsa CAPES/FULBRIGHT, de outubro a dezembro/2012.

2. Essas categorias serão explicadas posteriormente.

3. Disponível em: http://letramentoacademico.fflch.usp.br/

4. Mais informações em: http://en.unesco.org/

5. Uma das grandes contribuições do projeto foi a publicação: Motta-Roth, D. \& Hendges, G. H. (2010). Produção textual na universidade. São Paulo: Parábola Editorial.

\section{Referências}

BRONCKART, J. O Agir nos discursos: das concepções teóricas às concepções das trabalhadores. Traduzido por: MACHADO, A. R.; MATENCIO, M. L. Campinas, SP: Mercado das Letras, 2008.

Atividade de linguagem, discurso e desenvolvimento humano. $1^{\text {a }}$ ed. Trad. Anna Rachel Machado; Maria Lucia Meirelles Matencio. Campinas, Mercado de Letras, 2003;2006; 2009.

BULEA, E. Linguagem e efeitos desenvolvimentais da interpretação da atividade. Campinas, SP: Mercado de Letras, 2010.

CARNIN, A. Formação inicial, construção de objetos de ensino e transposição didática: do saber ao saberfazer. In: GUIMARÃES, A. M. M.; SCHNACK, C. M.; BICALHO, D. C. Práticas de letramento: caminhos e olhares inovadores. Porto Alegre: Editora Mediação, 2014, 13-40.

CASTELUBER, D. E. M. Formação de um leitor crítico: o trabalho com a compreensão do gênero carta do leitor em uma coleção didática. In: GUIMARÃES, A. M. M.; SCHNACK, C. M.; BICALHO, D. C. Práticas de letramento: caminhos e olhares inovadores. Porto Alegre: Editora Mediação, 2014, 163-192.

ILEES PROJECT. 2015. Disponível em: < http:// portuguese.ilees.org/> Acessado em 13 de agosto de 2015.

KLEIMAN, A. B. Preciso “ensinar” letramento? Não basta ensinar a ler e a escrever? Editora Cefiel, 2005.

.Letramento e suas implicações para o ensino de língua materna. Santa Cruz do Sul: Signo, v. 32, n. 53, p. 1-25, dez, 2007. Disponível em: < http:// www.letramento.iel.unicamp.br/publicacoes/artigos/ Letramento_e_implicacoes_Kleiman.pdf > Acessado em 20 de junho de 2015.

LABLER. 2015. Disponível em: <http://w3.ufsm.br/ labler/> Acessado em 30 de junho de 2015.

LABORATÓRIO DE LETRAMENTO ACADÊMICO. 2015. Disponível em: <http://letramentoacademico. fflch.usp.br/> Acessado em 30 de junho de 2015.

LEA, M. R.; STREET, B. V. O modelo de "letramentos acadêmicos": teoria e aplicações. Traduzido por: Fabiana Komesu e Adriana Fischer. São Paulo: Filol. Linguíst. Port. v. 16, n. 2, . 477-493, jul/dez. 2014.

MARCUSCHI, L. A. Da fala para a escrita: atividades de retextualização. São Paulo: Cortez, 2001.

RICHARDSON, R. J. et al. Pesquisa Social: métodos e técnicas. São Paulo: Atlas, 1985.

ROJO, R. Letramentos Múltiplos, escola e inclusão social. São Paulo: Parábola, 2009.

Recebido em: 01/03/2016 Aceito em: 20/07/2016 